\title{
Penerapan Model Traditional Flipped Learning Berbantuan LMS (Learning Management System) Edlink Pada Mahasiswa Pendidikan Bahasa Indonesia (Studi Kasus Di IKIP Budi Utomo Malang)
}

\author{
${ }^{1}$ Lis Susilawati, ${ }^{2}$ Nurwakhid Mulyono, \\ ${ }^{1,2}$ Prodi Pendidikan Bahasa dan Sastra Indonesia \\ ${ }^{1,2}$ IKIP Budi Utomo Malang \\ Surel: ${ }^{1}$ lhissusilawati@gmail.com, ${ }^{2}$ wakhidnur78@gmail.com
}

\begin{abstract}
ABSTRAK
Tujuan penelitian ini adalah untuk mengetahui penerapan media LMS (Learning Management System) Edlink terhadap keterlaksanaan model traditional flipped classroom pada mahasiswa Pendidikan Bahasa Indonesia IKIP Budi Utomo Malang. Metode yang Penelitian ini menggunakan metode kualitatif dengan menganalisis RPS Dosen, melakukan pengamatan terhadap pelaksanaan pembelajaran, dan melakukan wawancara dengan Dosen dan Ketua Program Studi. Teknik mendapatkan data, peneliti menggunakan alat pengumpulan data seperti RPS Dosen, lembar observasi dan teknik wawancara. Dari pengumpulan data, peneliti menyimpulkan bahwa: 1) dosen dapat mempersiapkan kegiatan pembelajaran dan $L M S$ Edlink dalam pelaksanaan flipped-classroom dalam rencana pembelajaran; 2) kinerja dosen dalam menggunakan LMS Edlink pada penerapan Flipped classroom dapat mengoptimalkan proses pembelajaran oleh mahasiswa; 3) saran yang diberikan kepada dosen agar dapat memperbaiki teknik mengajar maka, terdapat peningkatan belajar mahasiswa diterapkan model traditional flipped classroom berbantuan pada LMS (learning Management systems) Edlink pada Mahasiswa Pendidikan Bahasa Indonesia IKIP Budi Utomo Malang.

Kata Kunci: Traditional Flipped Clasroom,Learning Management System,Edlink
\end{abstract}

\begin{abstract}
ABSTRACK
The purpose of this study was to determine the application of Edlink's LMS (Learning Management System) media to the implementation of the traditional flipped classroom model for Indonesian Language Education students at IKIP Budi Utomo Malang. Methods This research uses qualitative methods by analyzing Lecturer's RPS, observing the implementation of learning, and conducting interviews with Lecturers and Head of Study Programs. Techniques for obtaining data, researchers used data collection tools such as Lecturer RPS, observation sheets and interview techniques. From the data collection, the researchers concluded that: 1) lecturers can prepare learning activities and LMS Edlink in the implementation of flipped-classroom in the lesson plan; 2) the performance of lecturers in using LMS Edlink in the application of the Flipped classroom can optimize the learning process by students; 3) suggestions given to lecturers in order to improve teaching techniques, there is an increase in student learning by applying the traditional flipped classroom model assisted by LMS (learning management systems) Edlink to Indonesian Language Education Students IKIP Budi Utomo Malang.
\end{abstract}

Key Word: Traditional Flipped Clasroom,Learning Management System,Edlink

\section{A. PENDAhUluan}

Perkembangan sains dan teknologi pada abad 21 mengharuskan adanya inovasi dan pembaharuan dalam kegiatan proses belajar mengajar untuk menghasilkan sumber daya manusia 
yang unggul, berkualitas dan kompetitif dalam menghadapi persaingan di era global sehingga diperlukan metode pembelajaran agar peserta didik tidak mudah bosan dalam menerima materi. (Rahajeng, Santyasa, \& Suswandi, 2018: 81). Era abad 21 pendidik maupun peserta didik harus mempunyai kemampuan belajar dan mengajar baik soft skill maupun hard skill. Kemampuan tersebut perlu adanya, dikarenakan style hidup manusia mengalami banyak perubahan yang signifikan, dalam dunia pendidikan pun mengalami perubahan yang diakibatkan adanya perkembangan kemajuan dan perkembangan science, technology, information, dan communication. Beberapa tantangan dan peluang pun muncul untuk dihadapi dan tidak bisa menghindar dari kemunculannya. Partikularitas yang terjadi pada abad 21 yaitu semakin berkaitan dan bersinerginya dunia ilmu pengetahuan satu dengan yang lainnya. Faktor waktu dan ruangpun semakin sempit. Abad 21 tersebut memperlihatkan keberhasilan dan kecepatan yang terjadi dalam berbagai konteks ilmu pengetahuan alam yang di dukung oleh dunia teknologi di dunia pendidikan (Maolidah, Ruhimat, \& Dewi, 2017).

Peraturan Menteri Pendidikan No 22 Tahun 2016 tentang Standar Proses Pendidikan Dasar dan Menengah, menyatakan bahwa "Kegiatan pembelajaran pada satuan pendidikan dilaksanakan secara interaktif, inspiratif, menyenangkan, menantang, memotivasi peserta didik untuk berpartisipasi aktif, dan memberikan ruang yang cukup bagi prakarsa, kreativitas, dan kemandirian sesuai dengan bakat, minat, dan perkembangan fisik serta psikologi peserta didik" (Kemendikbud, 2016). Pengembangan keterampilan abad ke-21 guru memiliki peranan. Peranan yang paling penting yaitu guru dapat menerapkan strategi inovatif dan teknologi pembelajaran modern yang dapat membantu mengintegrasian keterampilan kognitif dan sosial dengan pengetahuan serta peningkatan partisipasi peserta didik dalam hal pembelajaran untuk mempersiapkan soft skill di masa depan (Indriani, 2016). Pembelajaran dalam abad 21 berdasarkan k-13 yang diberlakukan di Indonesia yang fokus pembelajarannya tidak hanya dalam ranah kognitif tetapi dalam hal dominan spiritual, sosial, dan keterampilan (Indriani, 2016).

Salah satu jenis model blended learning adalah flipped classroom (pembelajaran terbalik). Ruang kelas terbalik adalah di mana siswa diperkenalkan dengan konsep yang sudah direkam sebelumnya (melalui internet, video, atau penulis rekaman audio-visual) di luar ruang instruksional tradisional (di rumah, di perpustakaan, atau di mana pun bahan ajar dapat diakses) (Bergmann \& Sams, 2012). Setelah menyaksikan materi, mahasiswa diharapkan masuk 
keruangan kelas, biasanya pada pertemuan kelas berikutnya dan berkolaborasi dengan temanteman dan guru tentang materi pembelajaran yang sudah ditentukan (Saunders, 2014). Siswa pada kelas terbalik diharapkan dapat menyelesaikan pekerjaan rumah di ruangan kelas dan mendiskusikan, menjelaskan, serta dapat memperluas konsep yang dipelajari dari materi online selama pembelajaran. Jadi, secara tradisional dilakukan siswa di rumah menjadi apa yang siswa lakukan di kelas, dan sebaliknya.

Hasil observasi pembelajaran di ruangan kelas peneliti dapat menyimpulkan bahwa kurangnya keterampilan berpikir kritis pada peserta didik waktu pembelajaran di kelas tidak sebanding dengan jumlah materi yang harus disampaikan oleh dosen. Selain itu metode yang digunakan dosen dalam pembelajaran cenderung membuat mahasiswa kurang aktif dan pada akhirnya kegiatan pembelajaran menjadi pasif dan masih berpusat pada guru serta masih belum memanfaatkan teknologi dalam proses pembelajaran. Oleh karena itu, perlu adanya suatu model pembelajaran yang dapat meningkatkan menunjang kegiatan pembelajaran dimana pembelajaran dapat diperoleh mahasiswa diluar dari hari efektifnya didalam ruangan kelas, sehingga mahasiswa dapat lebih aktif ketika proses pembelajaran dan teknologi dapat dimanfaatkan dalam pembelajaran. Model pembelajaran yang cocok untuk permasalahan tersebut yaitu model pembelajaran flipped classroom. Model ini merupakan suatu model yang menerapkan proses awal pembelajaran di rumah untuk memahami konsep atau materi dengan memakai fasilitas teknologi yang selanjutnya kegiatan pembelajaran di kelas dengan diskusi terkait materi yang belum dipahami (Yulietri, Mulyoto, \& S, 2015). Bergman dan Sams (2012) yang menyebutkan bahwa peserta didik pada saat ini bertumbuh dan berkembang dengan akses internet, YouTube, twitter, facebook, myscpae dan masih banyak lagi sumber digital lainnya. Pada kasus ini dosen belom seprnuhnya memanfaatkan LMS Edlink pada proses pembelajaran, sehingga pembelajaran cenderung membutuhkan waktu yang tidak sedikit untuk meningkatkan keterampilan pembelajaran mahasiswa ketika pembelajaran di dalam kelas. Hal tersebut mengakibatkan keterampilan berpikir kritis peserta didik rendah dan pembelajaran cenderung kurang aktif.

Kelebihan dari model pembelajaran flipped classroom menerapkan level kognitif berpikir tingkat tinggi (Higher Order Thinking Skills) di kelas dan di rumah. Pada model pembelajaran ini lebih mengutamakan peningkatan kemampuan keterampilan berpikir kritis peserta didik. Keterampilan berpikir kritis merupakan salah satu keterampilan pada kecakapan abad 21 yang 
perlu dimiliki oleh peserta didik. Pada keterampilan berpikir kritis peserta didik dituntut untuk dapat menggunakan penalaran deduktif dan induktif, membuat kesimpulan, menganalisis argumen, mengevaluasi atau menilai dan memecahkan masalah atau membuat keputusan. Keterampilan berpikir kritis bukan merupakan keterampilan bawaan semenjak lahir, akan tetapi dapat di latih, diterapkan, dan dikembangkan melalui suatu proses dan asesmenpembelajaran (Ritdamaya \& Suhandi, 2016: 88).

Model pembelajaran flipped classroom dapat mengatasi peserta didik ketika mengalami kesulitan atau hambatan pada saat belajar dengan cara 6 diselesaikan secara berdiskusi yang sesuai dengan sintaksnya yaitu fase 0 (Peserta didik belajar mandiri melalui video di rumah), fase 1 (Pembelajaran di kelas untuk melaksanakan kegiatan dan mengerjakan tugas), fase 2 (Menerapkan kemampuan peserta didik dalam proyek dan simulasi lain di dalam kelas), fase 3 (Mengukur pemahaman peserta didik yang dilaksanakan di kelas pada akhir materi pembelajaran) (Adhitiya, Prabowo, \& Arifuddin, 2015). Adapun kriteria pembelajaran dengan menggunakan model flipped classroom diantaranya: 1) waktu di kelas Edlink disediakan lebih banyak untuk asimilasi materi berupa latihan soal, atau aktivitas seperti diskusi, serta video pembejaran yang sudah dishare oleh dosen dll; 2) mengakomodasi adanya berbagai perbedaan mahassisdwa dalam hal motivasi, kemampuan menyerap materi dan pengetahuan sertan kemahirang memanfaatkan teknologi yang ada .

Dengan demikian peneliti menerapkan model pembelajaran flipped classroom pada penelitian dengan kebaharuan dari penelitian sebelumnya, yang mana penerapan model flipped classroom ini berbantuan LMS Edlink dapat diterapkan di mahasiswa pendidikan Bahasa Indonesia dalam proses kegiatan pembelajaran.

\section{B. KAJIAN TEORI}

Pembelajaran virtual didefinisikan sebagai pembelajaran di mana siswa dan guru dipisahkan oleh waktu dan ruang, atau keduanya, dan guru menggunakan Learning Management System (LMS) seperti Edlink untuk memberikan instruksi. Melalui software ini, guru dapat menawarkan instruksi terpadu (instruksi tatap muka yang mencakup akses ke materi pada LMS). Guru juga dapat menggunakan alat lain (Wikis, Blog) dan Video Conferencing untuk berkomunikasi dengan siswa. Inilah yang disebut dengan blended learning atau pembelajaran campuran atau kombinasi. Pada moda kombinasi ini, peserta melakukan interaksi belajar secara 
daring dan tatap muka. Interaksi belajar daring dilakukan secara mandiri dengan memanfaatkan teknologi informasi dan pembelajaran yang telah disiapkan secara elektronik, dan dapat dilakukan kapan saja dan dimana saja. Thorne (2003), mengartikan blended learning adalah perpaduan dari teknologi multimedia, CD ROM, video streaming, kelas virtual, voicemail, email dan telpon conference, animasi teks online dan video-streaming. Semua ini dikombinasi dengan bentuk tradisional pelatihan di kelas. Blended learning menjadi solusi yang paling tepat untuk proses pembelajaran yang sesuai tidak hanya dengan kebutuhan pembelajaran akan tetapi juga gaya belajar.

Pembelajaran online, sebagai bahan informasi dapat dilakukan dengan berbagai multimedia yaitu dengan menggabungkan teks, diagram, dan gambar dengan video dan suara sangat menunjang kemampuan mentransmisikan informasi yang bermakna dan bersifat maya (virtual). Keunggulan virtual class adalah untuk: 1) memberikan kesempatan belajar yang bisa dilakukan kapan saja dan dimana saja dengan menghemat waktu dan biaya, 2) meningkatkan keterampilan penggunaan teknologi informasi siswa sehingga siswa lebih kreatif dan menambah minat siswa untuk belajar, 3) memaksimalkan kemampuan masing-masing siswa dengan belajar diluar kelas tatap muka/kelas langsung.

Menentukan pembelajaran dengan model flipped classroom, harus didasarkan pada kebutuhan untuk: a) membantu siswa menguasai konsep atau pengetahuan tertentu yang rumit dan tidak dikuasai secara memadai melalui metode pembelajaran saat ini; b) melibatkan siswa dengan materi yang mungkin telah dianggap 'membosankan' atau 'tidak menarik' oleh kelompok masa lalu; dan/atau, c) memfasilitasi pengembangan keterampilan yang menggunakan pengetahuan atau konsep baru.

Menurut Bergman \& Sams ( 2012), menyatakan flipped classroom memiliki konsep dasar bahwa semua yang dilakukan di kelas pada pembelajaran konvensional menjadi dilakukan di rumah dan semua yang dilakukan sebagai pekerjaan rumah pada pembelajaran konvensional menjadi dilakukan di kelas. Definisi model pembelajaran flipped classroom (Knewton, 2011) dapat diilustrasikan dalam gambar 1 berikut. 


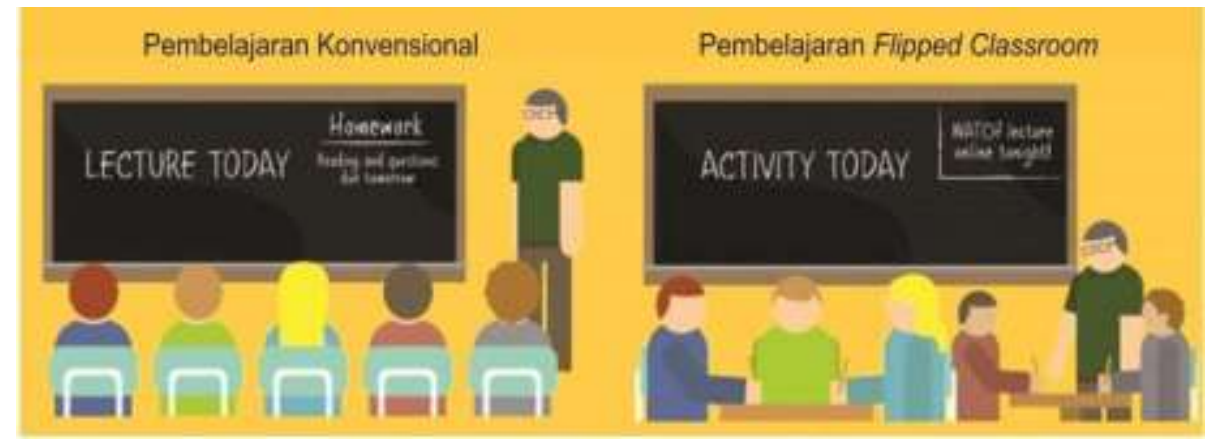

Gambar 1 Model Pembelajaran Flipped Classroom

\section{Langkah-Langkah Pembelajaran Flipped Classroom}

Model flipped classroom terbagi dalam beberapa tipe, beberapa di antaranya adalah traditional flipped classroom dan peer instruction flipped (Steele, 2013). Model pembelajaran traditional flipped sering digunakan oleh guru yang belum pernah menggunakan model flipped classroom sebelumnya. Pada model pembelajaran traditional flipped siswa diminta untuk menonton video pembelajaran atau media lainnya di rumah pada pembelajaran sebelumnya. Siswa mempersiapkan diri untuk mengikuti pembelajaran di kelas dengan belajar terlebih dahulu di rumah. Langkah selanjutnya adalah siswa datang ke kelas untuk melakukan kegiatan dan mengerjakan tugas yang berkaitan dengan materi pembelajaran. Di kelas siswa menerapkan kemampuan dalam proyek ataupun simulasi lainnya. Kegiatan yang berlangsung di kelas dapat dipandu menggunakan lembar kegiatan siswa (LKS). Tugas yang berkaitan juga diberikan dalam LKS. Kegiatan selanjutnya adalah mengukur pemahaman siswa dengan mengadakan kuis di akhir pembelajaran. Langkah-langkah pembelajaran traditional flipped menurut Steele (2013) sebagaimana digambarkan dalam gambar 3 berikut. 


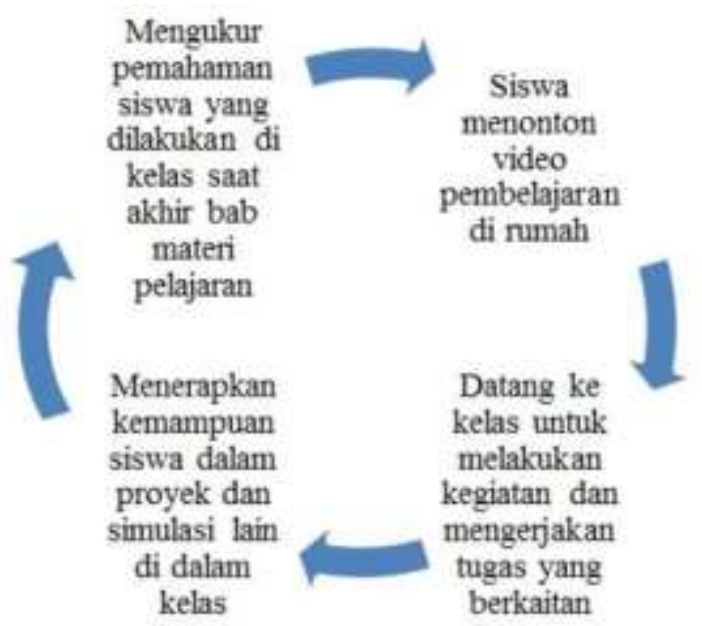

Gambar 2. Langkah-Langkah Pembelajaran Traditional Flipped

\section{Keunggulan pembelajaran flipped classroom}

Avgerinou (2008) menjelaskan tiga alasan penting kenapa seorang pengajar lebih memilih mengimplementasikan flipped classroom dibandingkan pembelajaran online maupun klasikal, yaitu: pembelajaran yang lebih baik, meningkatnya akses dan fleksibilitas, serta meningkatnya biaya- manfaat. Pendekatan yang berpusat pada siswa untuk mengajar mengalihkan fokus dari kebutuhan guru kepada siswa. Dan inilah yang didukung oleh model flipped classroom. Berbagai penelitian membuktikan bahwa model pembelajaran flipped classroom terbukti lebih efektif dalam meningkatkan kualitas pembelajaran dan keaktifan siswa pada sebuah proses pembelajaran dan memberikan hasil belajar yang lebih baik pula. Model pembelajaran ini juga sangat bermanfaat untuk guru dan siswa, karena :

a. Siswa dapat mengerjakan tugas mereka dengan didampingi oleh gurunya.

b. Sebelum lanjut ke materi berikutnya, guru dapat memastikan bahwa setiap siswa telah memahami konsep-konsep/materi yang harus dikuasai.

c. Motivasi belajar siswa meningkat dalam berkolaborasi, mengemukakan pendapat dan mengerjakan tugas bersama temannya.

d. Siswa dapat mempelajari kembali atau belajar secara mandiri apabila tidak dapat hadir di kelas, sedangkan guru dapat lebih leluasa meninjau dan meng-update rencana pembelajaran yang telah dilakukan.

e. Komunikasi antara guru dan siswa dapat terjalin dengan baik. 


\section{METODE PENELITIAN}

Penelitian ini dilaksanakan di IKIP Budi Utomo Malang pada Jurusan Pendidikan Bahasa Indonesia angkatan 2018 kelas A dan B yang berjumlah 70 mahasiswa. Adapun metode penelitian yang digunakan dalam penerapan model pembelajaran traditional flipped-classroom ini adalah metode kualitatif. Data dari Rencana Pembelajaran Semester (RPS), observasi, dan wawancara dengan dosen merupakan data utama yang digunakan untuk menganalisis proses penerapan didukung dengan wawancara dengan Ketua Prodi. Hasil analisis datanya selanjutnya digunakan untuk memberikan rekomendasi kepada ketua Prodi, dosen peneliti sendiri untuk meningkatkan kualitas penerapannya. Untuk memperoleh data tersebut, tiga instrumen yang digunakan adalah dokumen RPS, lembar observasi, dan panduan wawancara. RPS digunakan untuk menganalisis kesiapan Dosen dalam melakukan pembelajaran dan menganalisis kesiapan media yang dimanfaatkan untuk mendukung pembelajaran (procedural dan factual knowledge). Lembar observasi digunakan untuk menganalisis proses pembelajaran yang diselenggarakan oleh dosen (procedural, factual, conceptual, dan metakognition knowledge). Sementara, wawancara digunakan untuk mengetahui tingkat kesulitan dosen dalam menerapkan model pembelajaran traditional flipped-classroom berbatuan LMS Edlink dan pemanfaatan medianya (procedural dan conceptual knowleged). Terakhir, wawancara dengan ketua Program Studi untuk mengetahui tingkat kompetensi dosen modelnya (factual dan conceptual knowledge).

\section{HASIL PENELITIAN DAN PEMBAHASAN}

Pelaksanaan implementasi model pembelajaran dengan memanfaatkan multimedia diawali dengan studi kelayakan. Manikowati dan Utomo (2018) melaporkan bahwa IKIP Budi Utomo merupakan salah Perguruan Tinggi swasta yang ada di Kota Malang yang menerapkan model pembelajaran dengan memanfaatkan TIK, khususnya multimedia. Dari data yang diperoleh, Ketua Prodi memiliki kebijakan yang terbuka terhadap pemanfaatan TIK untuk pembelajaran meskipun jumlah perangkat yang dimiliki masih kurang memenuhi kuota mahasiswa. Selain itu, terdapat informasi bahwa pemanfaatan TIK di sekolah ini sudah berjalan dengan cukup baik. Sebagai tambahan, beberapa dosen ini sudah menerapkan model pembelajaran meskipun masih ada beberapa model pembelajaran inovatif yang belum diketahui dan kemampuan TIKnya masih pada 
tataran literasi. Berdasarkan kondisi yang diperoleh, IKIP Budi Utomo berada pada level literated infusing (masih ada beberapa model pembelajaran inovatif yang belum diketahui tetapi TIK dapat dimanfaatkan meski belum didukung oleh kompetensi TIK yang bagus dari para dosen). Memperhatikan kondisi tersebut, akhirnya diputuskan bahwa yang menjadi target capaian penerapan di Perguruan tinggi tersebut adalah implemented infusing (Pengetahuan guru terhadap model pembelajaran inovatif semakin meningkat dibarengi kemampuan TIK yang baik oleh para dosen sehingga dapat diterapkan dan dimanfaatkan dalam proses pembelajaran).

Analisis Persiapan Pembelajaran Berdasarkan RPS yang diterima, topik "Caption Text" tersebut disampaikan selama 4 jam pelajaran atau 4 x 50 menit, yang dibagi menjadi dua kali pertemuan. Capaian pembelajaran beserta indikator pencapaian pembelajaran termuat secara jelas di RPS. Pernyataan tujuan pembelajaran juga sesuai dengan pola baku ABCD- Audience, Behaviour, Condition, dan Degree. Keempat unsur tersebut tercakup di dalam tujuan pembelajaran. Berikut adalah pernyataan tujuan pembelajaran yang terdapat pada RPS Dosen. Melalui pendekatan saintifik, metode discovery learning, teknik membaca skimming dan scanning, dan melalui zoom meeting, mahasiswa dapat menganalisis fungsi sosial, struktur teks, dan unsur kebahasaan dari teks penyerta gambar, sesuai dengan konteks penggunaannya, menangkap makna dalam teks penyerta gambar, dan menyusun teks penyerta gambar, dengan memperhatikan fungsi sosial, struktur teks, dan unsur kebahasaan yang benar dan sesuai konteks dengan perilaku jujur, disiplin, tanggungjawab, peduli (gotong royong, kerjasama, toleran, damai), santun, responsif dan pro-aktif dan menunjukan sikap sebagai bagian dari solusi atas berbagai permasalahan dalam berinteraksi secara efektif dengan lingkungan sosial dan alam serta dalam menempatkan diri sebagai cerminan bangsa dalam pergaulan dunia. Meskipun demikian, terlihat dosen penyusun RPS masih kebingungan dalam memahami konsep strategi dan metode pembelajaran. Hal ini terlihat pula pada poin pendekatan/ model/ metode pada RPS-nya.

Observasi Proses Pembelajaran Pembelajaran yang diselenggarakan dosen pada saat pemantauan ini adalah pembelajaran untuk pertemuan ke-2 mengenai Caption Text. Sebelum dimulai, dosen menyetting terlebih dahulu peralatan dan media yang akan digunakan. Beliau memasang laptop dan mengakses edlink yang digunakan dapat beroperasi dengan baik. Pada awal proses pembelajaran, dosen memberikan salam dan menanyakan kondisi kesehatan para 
mahasiswa. Kemudian, dosen mengulas pembelajaran yang telah laksanakan sebelumnya. Selanjutnya, dengan menggunakan video scribe yang telah dibuat, beliau menampilkan kepada mahasiswa tentang caption text dari tugas yang telah dikirimkan mahasiswa saat di rumah. Pada kegiatan inti, mahasiswa diminta mengamati media yang ditayangkan. Selanjutnya, diminta menjawab pertanyaan seputar fungsi dan struktur caption text beserta language features-nya. Dalam hal ini mahasiswa diberikan beberapa contoh caption text agar mereka dapat mengumpulkan informasi dan mengasosiasikannya. Terakhir, beberapa mahasiswa ditunjuk oleh dosen untuk menyampaikan hasil belajar mereka secara lisan lewat aplikasi zoom di edlink. Pada kegiatan penutup, dosen memandu saja para mahsiswa untuk mereview pembelajaran yang telah dilaksanakan. Berikut adalah proses pembelajaran yang diselenggarakan dengan model flipped classroom dengan berbantuan LMS Edlink yang bisa diakses lewat crome/Mozilla.

Hasil Wawancara dengan dosen terhadap penerapan model pembelajaran flipped classroom merupakan data dukung yang dibutuhkan untuk mengendalikan kondisi pembelajaran yang diselenggarakan. Berdasarkan wawancara diperoleh data mengenai motivasi pemanfaatan LMS Edlink dalam pembelajaran, team working civitas akademika perguruan tinggi dalam menyelenggarakan model pembelajaran yang diterapkan, pelaksanaan penerapan, manfaat dan kendala penerapan model dan LMS Edlink dalam pembelajaran. Dari data yang diperoleh, para dosen sebenarnya sangat mendukung pemanfaatan LMS Edlink dalam pembelajaran karena sangat bermanfaat apabila digunakan sesuai yang seharusnya. Penggunaan laptop di kelas sangat membantu dosen dalam memberikan visualisasi materi kepada para mahasiswa. Pembelajaran lebih menarik karena dapat memanfaatkan banyak indra. Learning management systems edlink dapat digunakan untuk melakukan proses pembelajaran mulai dari simulasi dan demonstrasi, terutama jika bahan dan alat yang dibutuhkan tidak dimiliki oleh kampus. Pemanfaatan media sosial dan atau email juga sangat membantu dosen untuk mengefisiensikan pembelajaran yang diselenggarakan. Akan tetapi, penerapan model flipped classroom ini masih mengalami kendala karena membutuhkan persiapan lebih, biaya yang lebih, mudah disalahgunakan, dan sulit mengontrol pemakainya serta terkendalah jaringan bagi mahasiswa untuk mengakses edlink. Apalagi IKIP Budi Utomo merupakan salah satu perguruan tinggi yang mayoritas mahasiswa dari Nusa Tenggara timur yang bertempat tinggal daerah pelosok yang sulit dijangkau oleh jaringan 
internet . Hal ini membutuhkan team work yang baik, baik antar dosen maupun wali mahasiswa dengan tenaga kependidikan lainnya. Di IKIP Budi utomo, team working ini sudah terjalin, meskipun belum optimal partisipasinya. Memperhatikan data yang diperoleh, para dosen sebenarnya merasa dibantu ketika LMS Edlink dimanfaatkan dalam pembelajaran pun dengan menerapkan model flipped classroom. Apalagi, dalam pembelajaran yang diselenggarakan Disaat pandemic covid-19. Kekurangan waktu yang dialami IKIP Budi Utomo dapat diantisipasi dengan model ini. Akan tetapi, pelaksanaannya belum optimal karena belum optimalnya sumber daya manusia dan tingkat kesulitan yang dihadapi untuk persiapan maupun pengontrolan pembelajaran. Selain itu, kebutuhan yang lebih atas fasilitas sarana dan prasarana yang dibutuhkan juga menjadi kendala penerapannya

Hasil Wawancara dilaksanakan untuk memperoleh data mengenai kebijakan terhadap penerapan traditional learning tipe flipped classroom dengan memanfaatkan LMS Edlink. Data ini merupakan data dukung untuk mengendalikan model pembelajaran yang diterapkan. pada hakikatnya mendukung penerapan model blended learning, terutama tipe flipped classroom. Bahkan mahasiswa bisa memanfaatkan handphone untuk pembelajaran untuk mengakses LMS Edlink. Dari data tersebut terlihat bahwa IKIP Budi Utomo memiliki kebijakan yang baik sekali terhadap penerapan model blended learning tipe flipped classroom dengan mengggunakan LMS Edlink . Dukungan terhadap pemanfaatan sarana dan prasarana yang dimiliki sekolah untuk pembelajaran dimaksimalkan. Selain itu, kebijakan terhadap pemakaian handphone pun diijinkan agar pembelajaran yang diselenggarakan bisa optimal.

\section{E. KESIMPULAN}

Memperhatikan data dan informasi yang diperoleh, dapat disimpulkan beberapa hal sebagai berikut: 1) Penerapan model traditional flipped classroom dengan memanfaatkan LMS Edlink dapat dilaksanakan dengan baik. Dosen mempersiapkan Rencana Pembelajaran Semester (RPS) sebelum mengajar, melaksanakan pembelajaran sesuai rencana, dan menggunakan multimedia sesuai dengan kebutuhan topik yang disampaikan. 2) Secara umum dosen yang menjadi model penerapan Di IKIP Budi Utomo sudah mampu membuat RPS KKNI dengan baik. Akan tetapi, masih perlu di-upgrade pengetahuan mereka mengenai perbedaan antara strategi, 
model, dan metode pembelajaran di era merdeka belajar. 3) Kemampuan Dosen untuk menerapkan model pembelajaran pun sudah baik. Dosen dalam mengajar sudah sesuai dengan RPS yang dipersiapkan dan mampu menggunakan LMS Edlink dengan baik dan lancar serta sesuai kebutuhan pembelajaran. 4.)Kemampuan menyetting LMS Edlink dengan baik. 5)Dosen siap untuk mengimplementasikan model pembelajaran flipped classroom dengan memanfaatakan LMS Edlink. Hal ini karena Edlink membantu Dosen dalam meningkatkan motivasi mahasiswa dalam proses belajar disaat pandemic covid 19 dan 6) Flipped classroom menjadikan pembelajaran yang diselenggarakan menjadi lebih efisien.

\section{F. SARAN}

Perlu dilakukan penelitian lanjutan mengenai flipped classroom dengan memanfaatkan LMS Edlink untuk menambah fitur-fitur yang dapat meningkatkan semangat mahasiswa dalam proses pembelajaran sehingga tujuan pembelajaran dapat tercapai.

\section{DAFTAR PUSTAKA}

Aksoy, E. (2013). Flipped Classroom. Diakses 18 Oktober 2019. Online: https://ctl.tedu.edu.tr/sites/default/files/content_files/docs/flipped_model.pdf Bergmann, J., \& Sams, A. (2013). The Flipped Classroom. CSE, 17(3), 24-27. Online: www.acsi.org

Avgerinou, M.D. (2008). Blended Collaborative Learning For Action Research Training. Open Education, 4(1), 1-20.

Bergmann, J., \& Samsa , A. 2012. Flipped Your Classroom: Reach Every Student In Every Class Every Day. USA: ISTE

Braseby, A. M. (2014). The Flipped-Classroom. Diakses 18 Oktober 2019. Online: https://www.ideaedu.org Brown, B. A (2016). Understanding the flipped classroom: Types, uses, and reactions to a modern and evolving pedagogy. Culminating Projects in Teacher Development,12,1-26.Online: https://repository.stcloudstate.edu/cgi/viewcontent.cgi?referer=https://www.google.com /\&httpsredi r=1\&article=1010\&context=ed_etds

Daryanto, A. (2015). Blended Learning Models for Graduate Programs of Management and Business. Presented on Online and Blended Education for MM/MBA Programs. Telkom University Bandung. Unpublished 
Ediyanto. (2016). Penilaian Formatif dan Penilaian Sumatif. Diakses 18 Oktober 2019. Online: https://yudharta.ac.id/id/2016/11/penilaian-formatif-dan-penilaian-sumatif/

Karlsson, G., \& Janson, S. (2016). The Flipped Classroom: A Model for Active Student Learning. Sweden: Portland Press

Limited Manikowati \& Utomo, N. P. (2018). Sosialisasi Penerapan Model Pembelajaran Blended-Learning Dengan Memanfaatkan Multimedia: Laporan. Semarang: BPMPK. Unpublished

Manikowati \& Utomo, N. P. (2018). Pemantauan Penerapan Model Pembelajaran BlendedLearning Dengan Memanfaatkan Multimedia: Laporan. Semarang: BPMPK. Unpublished

Maolidah, S., I., Ruhimat, T., \& Dewi, L. 2017. Efektivitas Penerapan Model Pembelajaran Flipped Classroom Pada Peningkatan Kemampuan Berfikir Kritis Siswa. EDUTECHNOLOGIA, Tahun 3, Volume 3, Nomor 2

Millman, N. B. (2012). The flipped classroom strategy: What is it and how can it best be used? Distance Learning, 9(3), 85-87.

Mulyadi, D. (2015). Study Kebijakan Publik dan Pelayanan Publik. Bandung : Alfabeta.

Saunders, M.J., 2014. The Flipped Classroom: Its Effects on Student Academic Achievement, and Critical Thinking Skills in Mathematics in High Schools. 